\title{
Powering a 35W DC Metal Halide High Intensity Discharge (HID) Lamp Based UCC3305
}

\author{
Hui Zhang \& Fuzhong Wang \\ School of Science, Tianjin Polytechnic University \\ Tianjin 300160, China \\ E-mail: huizhang_09@163.com
}

\begin{abstract}
A high power density integrated electronic ballast for low wattage high intensity discharge (HID) lamp based UCC3305 is proposed in this paper. The UCC3305 integrates all of the functions required to control and drive one HID lamp. A highly efficient and reliable topology full-bridge inverter is adopted to supply the lamp with low-frequency square-wave positive and negative current avoiding acoustic resonances. The UCC3305 special microcontroller for HID ballast is used to raise control performance and simplify the control circuit. The presented circuit was verified with experimental results. A prototype of $35 \mathrm{~W}$ digital HID ballast has been built with the whole efficiency of $89 \%$.
\end{abstract}

Keywords: HID, UCC3305, Acoustic resonances

\section{Introduction}

Recent developments in HID (High Intensity Discharge) lamps have increasingly been attracting interest due to their highly efficient operation and excellent color characteristics. These lamps are suitable for various applications, including automobile headlamps and back lamps for projectors (Groot,1986, p.5) The HID lamps exhibit negative-resistance characteristics in the operating regions and lamp resistance varies as the time proceeds. Consequently, ballasts are needed, and high voltage is also needed to start lighting for the HID lamps. Many studies have been conducted on the ballasts for the HID lamps(Marchesan, 2006, pp.1107-1112).

Conventional ballasts, which operate at low frequencies $(50$ or $60 \mathrm{~Hz})$ are not the most practical solution, due to their large size, excessive weight and low efficiency. In order to reduce the size of the ballasts for HID lamps, high frequency $(1 \mathrm{k}-10 \mathrm{kHz})$ ballasts have been developed. However, the arc in the HID lamp tends to be unstable at specific frequency operation ranges. This phenomenon is called acoustic resonance. One method for avoiding this phenomenon is to operate at a frequency above this range. However, the switching loss on the ballast becomes greater as the operating frequency increases (Lin, 2006, pp.254-262). In order to reduce the switching loss, a resonant-type inverter is used to provide electronic ballast for a fluorescent lamp (Ribas, 2005, pp.1118-1123).

The authors have investigated several types of electronic ballasts for the HID lamps(Azcondo, 2007, pp.815-823). This paper presents a novel type ballast for the HID lamps without the acoustic resonance. The key feature of the circuit topology is the application of an integrated controller. The proposed circuit is very simple. It is composed of a DC/DC converter, DC/AC converter and an ignition circuit. The design and performance of this proposed circuit are described in this paper. Based on the theoretical and experimental results, the proposed ballast circuit is suitable for the HID lamps.

\section{Description of the UCC3305 controller}

Block diagram of the UCC3305 is showed in Figure.1.It has 28 pins.

The features of the UCC3305 HID controller are outlined below(Caceres, 1999, pp.134-141):

\footnotetext{
OV input protection

. Output fault protection/timing

. Power regulation vs. lamp voltage

. Lamp start-up/cool down simulation

. Current-mode control
} 
Fixed frequency operation

. DC or AC lamp drive capability

High current drive capability

On board charge pump to provide gate drive down to 6VDC

Adjustable start-up to steady-state current Ratio

\section{Function Description}

The UCC3305 integrates all of the functions required to control and drive one HID lamp. It contains a complete current mode pulse width modulator, a lamp power regulator, lamp temperature compensation, and total fault protection.

\subsection{Slope Compensation}

In addition to a complete current mode PWM, the UCC3305 HID Controller contains internal slope compensation (Cimador, 1990, pp.597-604), a valuable function which improves current loop stability for high duty cycles. Slope compensation is accomplished with an on-chip current ramp and an off-chip resistor RSL. Larger values of RSL give more slope compensation and a more stable feedback loop.

\subsection{Lamp Temperature Compensation}

Lamp temperature compensation is critical for automobile headlamps, because without compensation, light output varies dramatically from a cold lamp to one that is fully warmed up. The UCC3305 HID Controller contains sophisticated internal circuitry to anticipate lamp temperature and also to compensate for lamp temperature. The circuits anticipate lamp temperature by monitoring charge on capacitors which charge when the lamp is on and discharge when the lamp is off.

The UCC3305 HID Controller compensates for lamp temperature by driving the lamp with a higher lamp power when the lamp is cold and reducing the power to a normal operating level when the lamp is warmed up. The capacitors which set these time constants are external film capacitors CS and CW, and are connected to SLOPEC and WARMUPC. CS and $\mathrm{CW}$ are critical capacitors and must be selected to match the time-temperature relationship of the lamp. In addition to changing the power regulation point, the WARMUPC capacitor voltage also changes the short circuit lamp current. The ratio of cold short circuit current to warmed-up short circuit current is set by the resistor from ADJ to ground.

\subsection{Power Regulation}

Regulate power to the lamp within $+10 \%$ over a lamp voltage variation of 60 to100VDC. The LPOWER output of the UCC3305 is a voltage roughly proportional to lamp input power. The UCC3305 regulates constant lamp power over a wide range of lamp voltages.. For inputs to VOUTSENSE below $0.5 \mathrm{~V}$, such as would occur with a shorted lamp, the loop regulates constant load current. For inputs to VOUTSENSE greater than $0.82 \mathrm{~V}$, as might occur with a lamp that is open or not yet lit, the loop also regulates constant load current, but at a lower current than for a shorted lamp. In between those two voltages, the amplifier driving the LPOWER pin will sum the load current and load voltage and produce a signal roughly proportional to load power. The summing amplifier approximates power well enough to hold power within $10 \%$ over a factor of two in lamp voltage.

\section{Ballast Design}

HID Ballast Schematic is showed in Figure 2.This circuit shows the UCC3305 HID Lamp Controller IC in a fly back converter. The output of the converter is regulated at constant power, so that lamp intensity is relatively constant regardless of small lamp manufacturing variations.

\subsection{Full Bridge Output Stage}

The output of the flyback converter is directed to the AC lamp through a full bridge inverter. The full bridge is switched at a low frequency (typically 195Hz), so that the average lamp voltage is zero.

The low frequency switching is derived from the PWM oscillator. It is desirable to switch lamp polarity when running, but switching lamp polarity can interfere with clean starting. The UCC3305 has a logic output called NOTON which is high when the lamp is not running (Not On) and low when the lamp is running. This output is connected to the DIVPAUSE input so that the low frequency switching stops until the lamp is fully lit.

\subsection{Powering The UCC3305}

Conventional power MOSFETs require at least $8 \mathrm{~V}$ of gate drive to ensure high efficiency and low on resistance.Despite this requirement, the UCC3305 HID Controller can be used to build a ballast that will drive power MOSFETs well with input supplies as low as $5 \mathrm{~V}$ ! The UCC3305 does this using a charge pump.

In this typical application, power for the UCC3305 HID Controller IC is derived from a $6.8 \mathrm{~V}$ zener supply. This zener regulated supply gives the application overvoltage protection, reverse battery protection, low parts count,and low cost. 
The output of the $6.8 \mathrm{~V}$ zener supply drives the VCC pin of the UCC3305. VCC is the input to the UCC3305 charge pump. The charge pump generates a regulated $10 \mathrm{~V}$ supply on the BOOST output. This $10 \mathrm{~V}$ supply drives all other functions on the UCC3305.

\subsection{Protection From Over Voltage}

The most significant stresses in an automotive environment are the overvoltage conditions which can occur during load dump and double-battery jump start. At these times, the voltage into the ballast can go so high that even the most overdesigned power stage will be damaged.

\section{Experimental Results}

A prototype ballast with function of constant lamp-power control is built for HID lamp. The constant lamp-power control scheme is fulfilled by simultaneously sensing lamp voltage and lamp current to achieve constant instantaneous power for the HID lamp. The measured lamp voltage Vlamp and lamp current Ilamp are shown in Figure.3. The rms values of lamp voltage and current at steady state are $86.2 \mathrm{~V}$ and $0.4 \mathrm{~A}$, respectively. Due to low-frequency square-wave-driven ballast, no acoustic resonances occur: Moreover, the efficiency of the presented ballast is approximately $89 \%$.

\section{Conclusion}

The proposed ballast, combining a buck-boost-flyback converter with a Full-bridge inverter, is negative-voltage-driven and offers constant lamp-power control. A prototype ballast circuit has been built in order to drive a 35W HID lamp from $12 \mathrm{~V}$ battery $\mathrm{DC}$ voltage. The experimental results have demonstrated a low-frequency, square-wave-driven electronic ballast that is free of acoustic resonance, thus verifying the functionality of the proposed circuit.

\section{References}

Azcondo, F. J. and Zane, R. C. Branas. (2007). Design of resonant inverters for optimal efficiency over lamp life in electronic ballast with phase control[J]. Power Electron, 2007, 22(3):815-823.

Cáceres, R. O and Barbi, I. (1999). "A Boost DC-AC converter: analysis, design, and experimentation”, IEEE Transactions on Power Electronics, vol.14, pp. 134-141.

Cimador, G. and Prestifilippo, P. (1990). "An attractive new converter topology for AC/DC, DC/DC \& DC/AC power conversion”, $12^{\text {th }}$ International Telecommunications Energy Conference, pp. 597-604.

Groot, J. de and Vliet, J. V. (1986). The High-Pressure Sodium Lamp. 1st ed., Mac Millan Educational, London.

Lin, R. L. and Chen, Y. T.. (2006). Electronic ballast for fluorescent lamps with phase-locked loop control scheme[J]. Power Electron, 2006, 21(1): 254-262.

Marchesan, T. B., Cervi, M, Campos A.and Prado, R.N (2006). "A Family of Electronic Ballasts Integrating Power Factor Correction and Power Control Stages to Supply HPS Lamps", Conference Records of the IEEE IAS Annual Meeting, vol.3, pp. 1107-1112.

Ribas, J., Garcia, J., Cardesin, J., Dalla-Costa, M. A., Calleja ,J. A. and Corominas, E. L. (2005). "High Frequency Electronic Ballast for Metal Halide Lamps Based on a PLL Controlled Class E Resonant Inverter", Conference on IEEE Power Electronics Specialists, pp.1118-1123. 


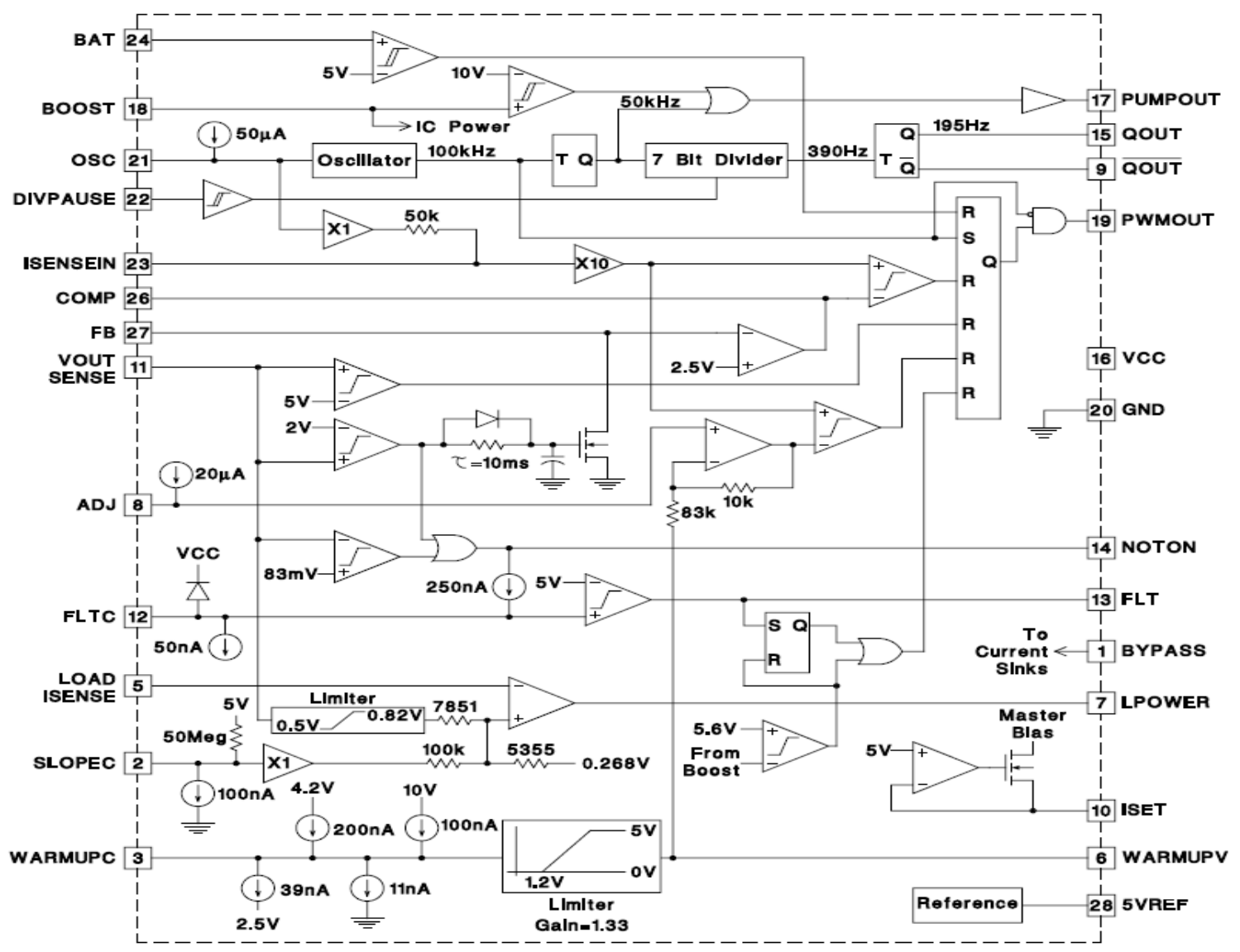

Figure 1. Block diagram of the UCC3305

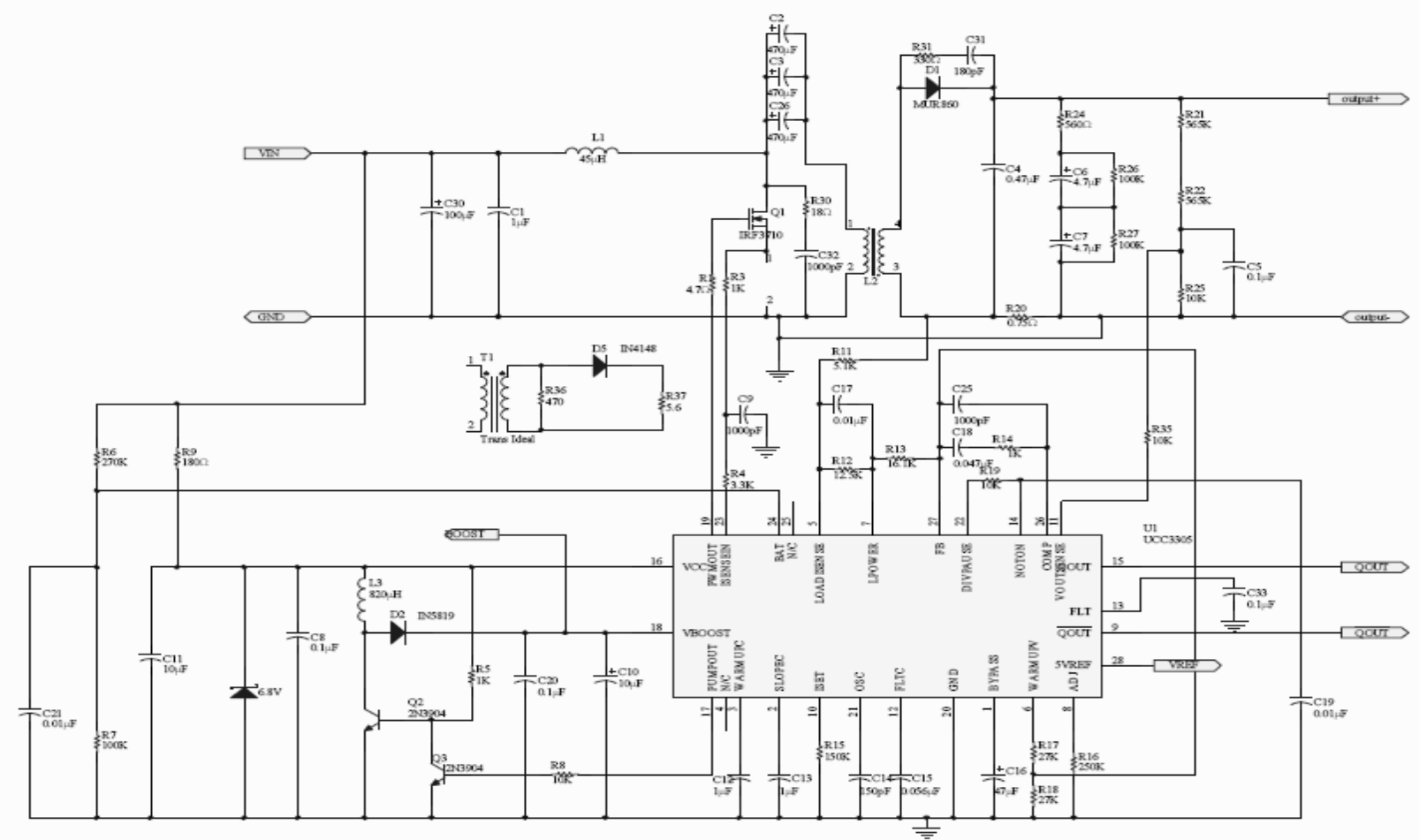

Figure 2. 35W DC HID Ballast Schematic 


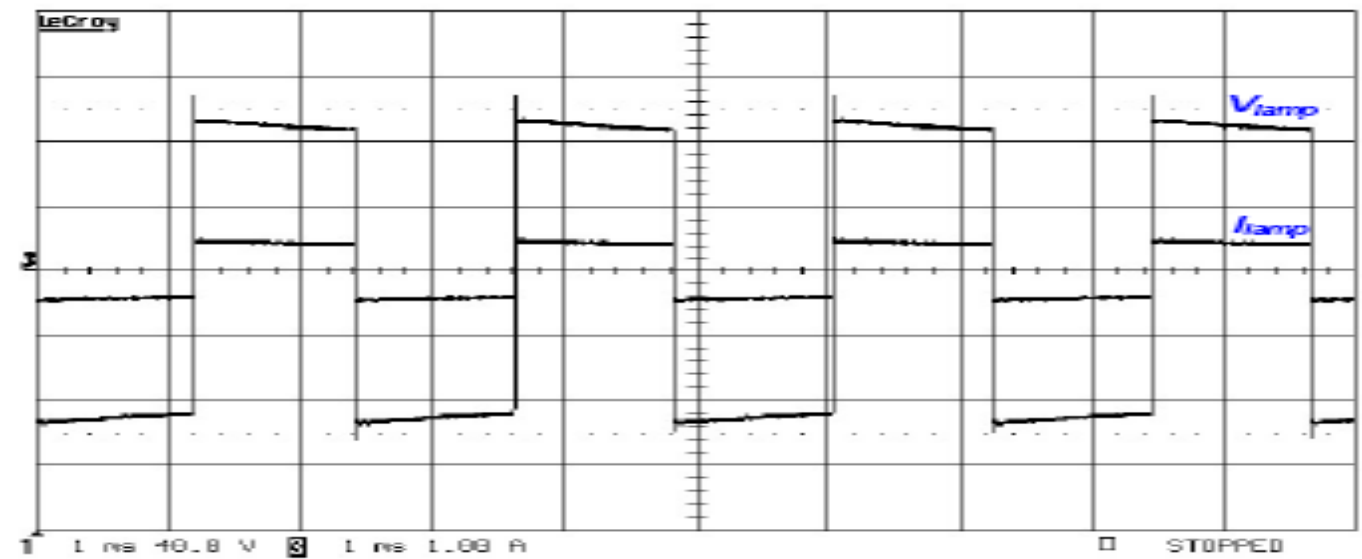

Figure 3. Lamp voltage Vlamp (40V/div) and current Ilamp (1A/div); time scale:1ms/div 